\title{
Características de carcaça e rendimento de buchada de caprinos alimentados com farelo grosso de trigo em substituição ao milho
}

\author{
Argélia Maria Araújo Dias ${ }^{2}$, Ângela Maria Vieira Batista ${ }^{3}$, Francisco Fernando Ramos de \\ Carvalho ${ }^{3}$, Adriana Guim ${ }^{3}$, Gilvan Silva ${ }^{4}$, Aline Candido da Silva ${ }^{5}$ \\ ${ }^{1}$ Projeto parcialmente financiado pela Bünge alimentos \\ 2 CODAI/UFRPE. \\ ${ }^{3}$ DZIUFRPE. Bolsista do CNPq. \\ ${ }^{4}$ Mestre em Zootecnia - UFRPE. \\ 5 Técnica agrícola - CODAI/UFRPE.
}

RESUMO - Objetivou-se determinar as características de carcaça e rendimento de buchada de caprinos alimentados com dietas com 0,0; 8,9; 19,8 ou 31,7\% de farelo grosso de trigo (FGT) em substituição ao milho. Foram utilizados 24 cabritos mestiços, machos não-castrados, com peso inicial de $20 \mathrm{~kg}$, em gaiolas individuais, distribuídos em delineamento inteiramente casualizado, com quatro dietas e seis repetições, durante 74 dias. Houve efeito linear decrescente nos pesos e rendimentos de carcaça quente e fria, enquanto o peso vivo ao abate $(27,85 \mathrm{~kg})$, as perdas por jejum $(4,02 \%)$, as perdas por resfriamento $(4,15 \%)$ e a área de olho-de-lombo $\left(7,2 \mathrm{~cm}^{2}\right)$ não foram influenciados pelo aumento do FGT na ração. Os pesos de lombo, perna e baixo e o percentual do baixo reduziram linearmente, enquanto o peso de buchada foi influenciado de forma quadrática (ponto de máximo 14,22\%) pela inclusão do FGT. Os melhores resultados de rendimentos de carcaça e buchada foram obtidos com a inclusão, em média, de $14 \%$ de farelo grosso de trigo em substituição ao milho.

Palavras-chave: carne, cortes comerciais, órgãos, subprodutos

\section{Carcass characteristics and buchada dressing of goat fed rough wheat bran replacing corn}

\begin{abstract}
The objective of this work was to evaluate the carcass characteristics and "buchada" dressing of goat fed with diets with $0.0,8.9,19.8$, and $31.7 \%$ of rough wheat bran (RWB) replacing corn. Twenty-four crossbred male goats, with initial $20 \mathrm{~kg} \mathrm{LW}$, in individual cages, allotted to a completely randomized experimental design with four diets and six replications, during 74 days. Hot and cold carcass weight and dressing decreased linearly, the slaughter live weight (27.85 kg), fasting losses $(4,02 \%)$, cooling losses $(4.15 \%)$, loin eye area $\left(7.2 \mathrm{~cm}^{2}\right)$ were not affected by increasing dietary RWB levels. The weights loin, leg, and breast weight, and percent of breast linearly reduced, while the "buchada" weight were quadratically affected (point of maximum 14.22\%) by the inclusion of RWB. The best results of carcass and buchada dressing were obtained with inclusion, in average, of $14 \%$ rough wheat bran replacing corn.
\end{abstract}

Key Words: by-products, commercial cuts, meat, organs

\section{Introdução}

O aumento na produção de carne caprina tem se expandido de forma expressiva nos últimos anos, o que pode ser atribuído principalmente às suas características dietéticas e sua aceitabilidade pelo consumidor. A carcaça caprina geralmente tem baixa quantidade de gordura de cobertura e gordura intramuscular (Tahir et al., 1994; Nogueira et al., 2004).

Entre os fatores que contribuem para os baixos índices de produção de carne caprina ao longo do ano, destaca-se a falta de alternativas alimentares para os animais. Nessas condições, o confinamento pode ser uma alternativa viável, principalmente quando se pretende intensificar o sistema de produção e melhorar a oferta de carne e qualidade das carcaças.

Considerando que a alimentação de cabras em sistema de confinamento representa mais de $60 \%$ do custo de produção (Leite, 1999), pesquisas com resíduos agroindustriais têm sido desenvolvidas visando à substituição total ou parcial de alimentos convencionais, como milho e soja. Entretanto, a redução nos custos de 
produção não deve prejudicar a qualidade da carcaça e aumentar a rentabilidade do sistema (Gonzaga Neto et al., 2006).

O farelo grosso de trigo (FGT) é um dos ingredientes que compõem o farelo de trigo normalmente comercializado para ração animal. Pouco se conhece sobre sua caracterização e utilização na alimentação animal e nenhuma pesquisa avaliando o desempenho e as características de carcaças de caprinos foi encontrada na literatura consultada. O conhecimento das características nutricionais do FGT e de outros constituintes do farelo de trigo pode agregar valor a esses produtos se sua comercialização for feita separadamente e não na forma de farelo de trigo.

No Nordeste, como os rebanhos são compostos predominantemente de animais de raças não especializadas para produção de carne e o manejo nutricional é deficiente, o abate é geralmente realizado tardiamente, quando os animais apresentam 25 a $30 \mathrm{~kg}$ de peso corporal, resultando em carcaças com média de 12 a 13 kg (Mattos et al., 2006).

A conformação e a composição da carcaça são muito importantes e devem ser consideradas quando se pretende introduzir novos alimentos na dieta dos animais, uma vez que essas características influenciam o rendimento de carcaça, a qualidade da carne e o retorno econômico do sistema de exploração (Santana et al., 2004).

Os principais fatores que determinam as características qualitativas e quantitativas da carcaça são o sexo, a idade, o genótipo e o sistema de produção e nutrição (Bueno et al., 1999; Dhanda et al., 1999; Cameron et al., 2001). O rendimento de carcaça quente na espécie caprina varia de 41 a 56\% (El Khidir et al., 1998; Johnson \& Mcgowan, 1998; Bueno et al., 1999; Moore et al., 2002), enquanto o rendimento de carcaça fria varia de 38 a 51\% (El khidir et al., 1998; Bueno et al., 1999; Yamamoto et al., 2000; Zundt et al., 2001).

No Brasil não existe padronização na comercialização da carcaça caprina nem de seus cortes (Yánez, 2002) e geralmente têm-se adotado métodos europeus, principalmente o espanhol e o francês, com algumas modificações, em virtude do hábito alimentar de seus consumidores (Silva Sobrinho \& Gonzaga Neto, 2004).

No Nordeste Brasileiro, é comum a utilização de alguns componentes não-carcaça (CNC) na culinária em tradicionais pratos como "sarapatel” e "buchada" (Silva Sobrinho \& Gonzaga Neto, 2004).

Este trabalho foi realizado para avaliar o efeito da inclusão de farelo grosso de trigo em substituição ao milho em dietas para caprinos sobre o peso ao abate, as características de carcaça, os cortes comerciais e o rendimento de buchada.

\section{Material e Métodos}

O trabalho foi conduzido no Setor de Caprinoculturaovinocultura, do Departamento de Zootecnia da Universidade Federal Rural de Pernambuco, em Recife, Pernambuco, situado na microrregião fisiográfica da Zona da Mata, durante ano de 2004. Foram utilizados 24 cabritos mestiços Anglonubianos, machos não-castrados, com peso vivo médio de 20 kg e 6 a 7 meses de idade, dispostos em delineamento inteiramente ao acaso (DIC).

Os animais foram identificados, pesados e tratados contra ecto e endoparasitos. Foram alojados em baias individuais de madeira medindo $1,20 \mathrm{~m} \times 0,72 \mathrm{~m}$, com acesso a comedouros e bebedouros. Avaliaram-se quatro dietas (tratamentos), formuladas com $50 \%$ de feno de capim-tifton 85 e $50 \%$ de concentrado contendo $0 ; 8,9 ; 19,8$ ou $31,7 \%$ de FGT.

As dietas foram formuladas para atender aos requerimentos de ganhos médios diários de $150 \mathrm{~g} / \mathrm{animal} / \mathrm{dia}$, segundo o NRC (1985) (Tabela 1). O experimento teve duração de 64 dias, incluindo o período pré-experimental de 14 dias.

As pesagens foram realizadas ao início (PVI) e término (PVF) do período experimental. Antes do abate, os animais foram pesados em jejum completo de 18 horas. Em seguida, foram novamente pesados (PVA) objetivando determinar a perda de peso durante o jejum (PJ\%), expressa como $\mathrm{PJ}(\%)=\mathrm{PVF}-\mathrm{PVA} / \mathrm{PVA} * 100$.

Tabela 1 - Composição das dietas experimentais (\%MS)

\begin{tabular}{|c|c|c|c|c|}
\hline \multirow[t]{2}{*}{ Item } & \multicolumn{4}{|c|}{ Nível de farelo grosso de trigo (\%) } \\
\hline & 0,0 & 8,9 & 19,8 & 31,7 \\
\hline \multicolumn{5}{|l|}{ Ingrediente } \\
\hline Milho & 25,2 & 18,1 & 9,7 & 0 \\
\hline Farelo grosso de trigo & 0 & 8,9 & 19,8 & 31,7 \\
\hline Feno de capim-tifton & 50 & 50 & 50 & 50 \\
\hline Farelo de soja & 23,8 & 22,0 & 19,5 & 17,3 \\
\hline Sal mineral & 0,5 & 0,5 & 0,5 & 0,5 \\
\hline Calcário & 0,5 & 0,5 & 0,5 & 0,5 \\
\hline \multicolumn{5}{|l|}{ Composição química (\%) } \\
\hline Matéria seca & 85,4 & 85,5 & 85,7 & 85,8 \\
\hline Matéria orgânica ${ }^{1}$ & 93,6 & 93,3 & 92,4 & 92,5 \\
\hline Proteína bruta ${ }^{2}$ & 19,5 & 19,3 & 19,1 & 19,0 \\
\hline Extrato etéreo ${ }^{3}$ & 2,3 & 2,3 & 2,2 & 2,2 \\
\hline Fibra detergente neutro ${ }^{4}$ & 46,0 & 48,9 & 52,6 & 56,5 \\
\hline $\begin{array}{l}\text { Fibra em detergente neutro } \\
\text { corrigido para proteína }{ }^{5}\end{array}$ & 43,6 & 46,1 & 49,3 & 52,7 \\
\hline Fibra em detergente ácido 6 & 22,9 & 23,8 & 24,8 & 25,9 \\
\hline Carboidratos totais 7 & 71,9 & 71,7 & 71,6 & 71,3 \\
\hline Carboidratos não fibrosos ${ }^{8}$ & 28,3 & 25,5 & 22,3 & 18,6 \\
\hline Nutrientes digestíveis totais 9 & 66,3 & 64,9 & 63,2 & 61,3 \\
\hline
\end{tabular}

${ }^{1}$ Porcentagem com base na matéria seca. 
O abate foi realizado por meio de insensibilização, seguida de sangria e esfola. O sangue foi recolhido, pesado e registrado. Após a esfola, realizaram-se a evisceração e a retirada do trato gastrintestinal (TGI). As vísceras foram individualmente pesadas, cheias e vazias, para determinação do conteúdo do trato gastrintestinal (CTGI). O peso de corpo vazio (PCVz) foi obtido pela diferença entre o peso de abate e do conteúdo gastrintestinal.

O peso da carcaça quente foi obtido por meio da retirada da cabeça, das extremidades dos membros e dos órgãos genitais, incluindo cauda rins e gordura pélvica e renal. As carcaças quentes foram pesadas (PCQ) para determinação do rendimento de carcaça quente $(\mathrm{RCQ}=\mathrm{PCQ} / \mathrm{PVA} \times 100)$. Avaliou-se também o rendimento biológico ou verdadeiro (RV), calculado pela relação RV (\%) = PCQ/PCVz*100.

Para obtenção do peso de carcaça fria (PCF), após a obtenção do PCVz as carcaças foram identificadas e mantidas em câmara fria $\left(4^{\circ} \mathrm{C}\right)$, penduradas pelas articulações tarsometatarsianas, por 24 horas a $4^{\circ} \mathrm{C}$. Após a pesagem, procedeu-se à retirada dos rins, da gordura pélvica renal e da cauda. A perda de peso por resfriamento (PR) e o rendimento da carcaça fria ou comercial (RC) foram determinados pelas expressões: PR (\%) = (PCQ $-\mathrm{PCF} / \mathrm{PCQ}) * 100$; $\mathrm{RC}(\%)=(\mathrm{PCF} / \mathrm{PVA}) * 100$, respectivamente.

A área de olho-de-lombo (AOL) foi medida entre a 12 $12^{\mathrm{a}}$ e13 $3^{\text {a }}$ costelas, com auxílio de um planímetro.

Os cortes comerciais foram realizados após a retirada da cauda; as carcaças foram divididas longitudinalmente, na altura da linha média, para obtenção das meias-carcaças direita e esquerda, que foram seccionadas em seis regiões anatômicas: pescoço (1ㅁa a 7므 vértebra cervical), paleta (base óssea:escápula, úmero e carpo), costelas (1 $1^{\mathrm{a}}$ a $13^{\underline{a}}$ vértebra torácica), lombo (secção entre a 1aㅡ e a $6 \underline{\underline{a}}$ vértebra lombar), perna (secção entre a última vértebra lombar e a primeira sacra) e baixo (secção em linha reta partindo do flanco até a articulação escápulo-umeral), adaptado de ColomerRocher (1987) e Yáñez (2002). Cada peça da meia-arcaça esquerda foi pesada individualmente e depois pesada junta com sua peça correspondente da carcaça direita para posterior determinação de seu peso em porcentagem da soma das meias-carcaças.

O rendimento de buchada foi determinado com base no peso da buchada (somatório do sangue, fígado, rins, pulmões, baço, língua, coração, omento, rúmen-retículo, omaso e intestino delgado) em relação ao peso vivo do animal ao abate.

As análises estatísticas das características estudadas foram interpretadas por análises de variância e regressão, de acordo com os níveis de farelo grosso de trigo nas dietas experimentais (SAS, 1999).

\section{Resultados e Discussão}

Os consumos de matéria seca (MS) foram, respectivamente, 769,2; 885,7; 866,5 e 731,5 g/dia nos animais alimentados com as dietas contendo $0 ; 8,9 ; 19,8$ e 31,71\% de FGT, portanto, foram influenciados ( $\mathrm{P}>0,05)$ pelo nível de fibra na ração. O maior consumo MS foi obtido com a inclusão de $14,54 \%$ de farelo grosso de trigo, que corresponde a aproximadamente $46,0 \%$ de substituição do milho.

O peso vivo ao abate, o peso do corpo vazio e o percentual de perdas ao jejum não foram influenciados $(\mathrm{P}>0,05)$ pelo nível de farelo grosso de trigo na dieta. As médias para essas características foram, respectivamente, de 27,86 kg; 23,14 kg e 4,05 (Tabela 2). Contudo, houve redução linear $(\mathrm{P}<0,05)$ dos pesos da carcaça quente e fria e aumento linear $(\mathrm{P}<0,05)$ do conteúdo do trato gastrintestinal com a inclusão do farelo grosso de trigo (FGT) na dieta.

Os rendimentos das carcaças quente e fria (Tabela 2) reduziram linearmente $(\mathrm{P}<0,05)$ com a inclusão de FGT na dieta, enquanto o rendimento verdadeiro, as perdas no resfriamento e a área de olho-de-lombo não foram influenciados $(\mathrm{P}>0,05)$ pela inclusão de farelo grosso de trigo.

A redução linear nos pesos e rendimentos de carcaça pode ser atribuída ao aumento nos níveis de fibra e à redução dos carboidratos não-fibrosos (CNF), em virtude da inclusão de FGT nas dietas (Tabela 1). Esse efeito pode ser confirmado pelo aumento linear no conteúdo do trato gastrintestinal (Tabela 2), o que possivelmente limitou o consumo, em razão do maior tempo de permanência da fibra no rúmen-retículo. Além disso, houve redução no consumo de NDT com o aumento de FGT nas dietas, fato observado também por Dias (2006), que encontraram valores de 536,9; 618,9; 593,0 e 478,4 g de NDT/dia, respectivamente, para os animais submetidos às dietas contendo 0,$0 ; 8,9 ; 19,8$ e 31,7\% de FGT.

Logo, a redução no aporte energético aos animais com o aumento de FGT nas dietas experimentais refletiu negativamente nos pesos e rendimentos de carcaça (Tabela 2).

O rendimento biológico diferiu significativamente com a eliminação do conteúdo total gastrintestinal. Esse comportamento está de acordo com o relatado por Zundt et al. (2001), que não verificaram efeito significativo dos níveis de energia da dieta sobre o rendimento biológico de caprinos.

Segundo Silva Sobrinho (1999), a perda de peso por resfriamento (PPR) é maior em carcaças com menor quantidade de gordura de cobertura. Considerando a redução linear $(\mathrm{P}<0,05)$ da concentração de gordura subcutânea na perna caprina observada por Dias (2006) em animais alimentados com dietas contendo farelo grosso de trigo, espera- 
Tabela 2 - Características de carcaça de caprinos alimentados com dietas contendo farelo grosso de trigo

\begin{tabular}{|c|c|c|c|c|c|c|c|}
\hline Item & \multicolumn{4}{|c|}{ Nível de farelo grosso de trigo (\%) } & $\mathrm{CV} \%$ & Regressão & $\mathrm{R}^{2}$ \\
\hline Peso vivo ao abate ${ }^{1}(\mathrm{~kg})$ & 27,6 & 29,6 & 28,5 & 25,7 & 10,4 & $\hat{\mathrm{Y}}=27,85^{\mathrm{ns}}$ & - \\
\hline Perda aо jejum (\%) & 4,2 & 3,5 & 3,7 & 4,7 & 48,6 & $\hat{\mathrm{Y}}=4,02^{\mathrm{ns}}$ & - \\
\hline Peso do corpo vazio (kg) & 23,4 & 25,3 & 23,3 & 20,6 & 11,4 & $\hat{\mathrm{Y}}=23,15^{\mathrm{ns}}$ & - \\
\hline Conteúdo do $\mathrm{TGI}^{2}$ (kg) & 4,2 & 4,2 & 5,1 & 5,2 & 14,4 & $\hat{Y}=4,1071+0,03747 X$ & 0,76 \\
\hline Peso carcaça fria $^{4}(\mathrm{~kg})$ & 12,1 & 12,7 & 11,8 & 9,9 & 13,9 & $\hat{Y}=12,8263-0,07245 X$ & 0,65 \\
\hline Rend. carcaça quente ${ }^{5}$ (\%) & 45,7 & 45,0 & 43,1 & 40,2 & 6,0 & $\hat{Y}=46,2088-0,17299 X$ & 0,94 \\
\hline Rend. carcaça fria ${ }^{6}$ (\%) & 43,8 & 43,1 & 41,5 & 38,3 & 6,1 & $\hat{Y}=44,3443-0,17012 X$ & 0,94 \\
\hline Rendimento biologico (\%) & 53,9 & 52,5 & 52,7 & 50,4 & 4,5 & $\hat{\mathrm{Y}}=52,37^{\mathrm{ns}}$ & - \\
\hline
\end{tabular}

${ }^{1}$ Não-significativo $(P>0,05) ;{ }^{2}$ Conteúdo do trato gastrintestinal CTGI $(P<0,01) ;{ }^{3}(P<0,03) ;{ }^{4}(P<0,03) ;{ }^{5}(P<0,01) ;{ }^{6}(P<0,01)$.

vam-se maiores perdas por resfriamento com a inclusão do FGT na dieta, no entanto, não foram registradas diferenças significativas ( $\mathrm{P}>0,05)$ para essa variável, cujo valor médio foi 4,15\%. Gonzaga Neto et al. (2006) encontraram valor médio de 4,89\% ao estudarem as características de carcaça de cordeiros.

No estudo de correlações da área de olho-de-lombo (AOL) com PCQ, PCF e PCVz, foram obtidos valores de r de 0,$79 ; 0,78$ e 0,75 , respectivamente, o que comprova a elevada correlação entre as variáveis analisadas. Valores médios de AOL com 8,8 $\mathrm{cm}^{2}$ foram encontrados por Johnson \& Mcgowan (1998), ao avaliarem o efeito do manejo e da dieta sobre as características de carcaça em caprinos.

O aumento no nível de FGT na dieta dos caprinos provocou decréscimo linear $(\mathrm{P}<0,05)$ nos pesos de lombo, perna e baixo, mas não afetou os pesos de pescoço, paleta e costela dos animais $(\mathrm{P}>0,05)$.

Quando os cortes foram expressos em porcentagem, não houve diferença significativa $(\mathrm{P}>0,05)$ entre os níveis de FGT. O baixo, no entanto, reduziu linearmente $(\mathrm{P}<0,05)$ com o aumento de FGT na ração. Essa similaridade na porcentagem dos cortes está relacionada à lei da harmonia anatômica (Boccard \& Dumont 1960, citado por Siqueira et al., 2001) de que, em carcaça com peso e quantidade de gordura similares, quase todas as regiões corporais têm proporções semelhantes. Na comparação percentual (Tabela 3), a perna foi o corte com maior rendimento, seguida pela paleta e pelas costelas. O valor da perna foi próximo aos relatados por Sen et al. (2004) em estudo com caprinos em clima semi-árido alimentados com dietas com relação volumoso:concentrado de 50:50. Esses autores observaram rendimento de $28,19 \%$ para a perna, que, em virtude de sua maior musculosidade, apresenta maior rendimento da parte comestível (Silva Sobrinho, 2002).

Verificou-se efeito quadrático $(\mathrm{P}>0,05)$ dos níveis de FGT sobre o peso da "buchada”, cujo ponto de máxima foi 14,22\%. Para cabeça e patas, não houve efeito da substituição do milho por FGT (Tabela 4).

A buchada compreende o somatório dos pesos de sangue, fígado, rins, pulmões, baço, língua, coração, omento, rúmen-retículo, omaso e intestino delgado. $\mathrm{Na}$ região metropolitana do Recife, Pernambuco, e nos municípios próximos, a buchada inclui cabeça e patas. Para que esses componentes sejam comercializados em conjunto com a "buchada", são submetidos a um processo de limpeza no qual são retirados em torno de 50\% de componentes não-comestíveis, como a pele da cabeça e das patas, as orelhas, os olhos, todo o chanfro e os maxilares superior e inferior. Além disso, são submetidos a précozimento (Medeiros et al., 2006).

Considerando o somatório dos pesos da buchada (3,77 kg) com o de cabeça e patas após limpeza e précozimento (1,28 kg), são obtidos em torno de $5,05 \mathrm{~kg}$, que são comercializados a preço médio de R \$3,90/kg. Esse peso representa aproximadamente $18 \%$ do rendimento total em relação ao peso vivo ao abate e está de acordo com os descritos por Costa et al. (2003), que observaram rendimentos de buchada caprina de 18,73 e 18,82\% e computaram toda a gordura omental e mensentérica, os intestinos e o sangue no produto.

A utilização de vísceras comestíveis no preparo de pratos como a buchada pode ser uma excelente e viável alternativa econômica, pois agrega valor e aumenta a lucratividade da produção gerando renda adicional ao 
Tabela 3 - Pesos $(\mathrm{kg})$ e rendimento (\%) dos cortes comerciais de caprinos alimentados com dieta contendo farelo grosso de trigo

\begin{tabular}{|c|c|c|c|c|c|c|c|}
\hline Item & \multicolumn{4}{|c|}{ Nível de farelo grosso de trigo (\%) } & $\mathrm{CV} \%$ & Regressão & $\mathrm{R}^{2}$ \\
\hline Pescoço & 1,52 & 1,47 & 1,35 & 1,25 & 23,4 & $\hat{\mathrm{Y}}=1,40^{\mathrm{ns} 1}$ & - \\
\hline Costela & 2,11 & 2,22 & 2,04 & 1,8 & 14,6 & $\hat{\mathrm{Y}}=2,04^{\mathrm{ns}}$ & - \\
\hline Lombo $^{2}$ & 1,17 & 1,25 & 1,18 & 0,90 & 15,4 & $\hat{Y}=1,2569-0,0083 X$ & 0,56 \\
\hline (\%)Pescoço & 12,37 & 11,32 & 11,40 & 12,09 & 15,7 & $\hat{\mathrm{Y}}=11,79^{\mathrm{ns}}$ & - \\
\hline Paleta & 20,58 & 20,87 & 20,43 & 21,37 & 3,3 & $\hat{\mathrm{Y}}=20,81^{\mathrm{ns}}$ & - \\
\hline Costela & 17,38 & 17,22 & 17,22 & 17,7 & 4,0 & $\hat{\mathrm{Y}}=17,38^{\mathrm{ns}}$ & - \\
\hline Lombo & 9,58 & 9,71 & 9,91 & 8,85 & 8,2 & $\hat{\mathrm{Y}}=9,51^{\mathrm{ns}}$ & - \\
\hline
\end{tabular}

${ }^{1}$ Não significativos $(P>0,05) ;{ }^{2}(P<0,01) ;{ }^{3}(P<0,04) ;{ }^{4}(P<0,001) ;{ }^{5}(P<0,01)$.

Tabela 4 - Rendimento de componentes comestíveis de caprinos alimentados com dietas contendo farelo grosso de trigo

\begin{tabular}{lccccccc}
\hline Item & \multicolumn{3}{c}{ Nível de farelo grosso de trigo (\%) } & & CV\% & \multicolumn{2}{c}{ Regressão } \\
\cline { 2 - 5 } & 0 & 8,9 & 19,8 & 31,7 & & \\
\hline 1Buchada, kg & 3,6 & 4,0 & 4,0 & 3,4 & 11,7 & $\hat{\mathrm{Y}}=3,6452+0,06199 \mathrm{X}-0,0022 \mathrm{X}^{2}$ & 0,94 \\
Rendimento da buchada (\%PVA) & 13,2 & 13,5 & 14,0 & 13,3 & 6,6 & $\hat{\mathrm{Y}}=13,5$ & - \\
Cabeça e patas , kg & 2,6 & 2,6 & 2,6 & 2,5 & 10,9 & $\hat{\mathrm{Y}}=2,57$ & $\hat{\mathrm{Y}}=9,2$ \\
Cabeça e patas:PVA & 9,4 & 8,9 & 8,9 & 9,6 & 7,4 & - \\
\hline
\end{tabular}

${ }^{1}$ Somatório dos pesos do sangue, fígado, rins, pulmões, baço, língua, coração, omento, rúmen-retículo, omaso e intestino delgado ( $\left.\mathrm{P}<0,01\right)$.

produtor (Costa et al., 2005; Santos et al., 2005). A inclusão de até14,22\% de FGT na dieta de caprinos resulta em aumento linear no peso de buchada, que pode possibilitar a obtenção de maior renda na comercialização desses animais.

\section{Conclusões}

A substituição de $14 \%$ do milho por farelo grosso trigo na dieta de caprinos proporciona melhores resultados de rendimentos de carcaça e buchada.

\section{Literatura Citada}

BUENO, M.S.; SANTOS, L.E.; CUNHA, E.A. et al. Avaliação de carcaças de cabritos abatidos com diferentes pesos vivos. Revista Nacional da Carne, n.273, p.72-79, 1999.

CAMERON, M.R.; LUO, J.; SAHLU, T. et al. Growth and slaughter traits of Boer x Spanish, Boer x Angora and Spanish goat consuming a concentrate-based diet. Journal Animal Science, v.79, p.1423-1430, 2001.

COSTA, R.G.; MEDEIROS, A.N.; MADRUGA, M.S. et al. In: SIMPÓSIO INTERNACIONAL SOBRE CAPRINOS E OVINOS DE CORTE, 2., 2003, João Pessoa. Anais...João Pessoa: EMEPA, 2003. (CD-ROM).

COSTA, R.G.; SANTOS, N.M.; MEDEIROS, A.N. et al. Constituição da buchada caprina pré-cozida produzida no Estado da Paraíba. In: REUNIAO ANUAL DA SOCIEDADE BRASILEIRA DE
ZOOTECNIA, 42., 2005, Goiânia. Anais... Goiânia: Sociedade Brasileira de Zootecnia, 2005. (CD-ROM).

COLOMER-ROCHER, F.; MORAND-FEHR, P.; KIRTON, A.H. Standard methods and procedures for goat carcass evaluation, jointing and tissue separation. Livestock Production Science, v.17, p.149-159, 1987.

DHANDA, J.S.; TAYLOR, D.G; McCOSKER, J.E. et al. The influence of goat genotype on the production of capretto and chevon carcasses. 1. Growth and carcass characteristics. Meat Science, v. 52, p.355-361, 1999.

DIAS, A.M.A. Utilização do farelo grosso de trigo na alimentação de caprino. Recife: Universidade Federal Rural de Pernambuco, 2006. 120p. Tese (Doutorado em Zootecnia) Universidade Federal Rural de Pernambuco, 2006.

EL KHIDIR, I.A.; BABIKER, S.A.; SHAFIE, S.A. Comparative feedlot performance and carcass characttristics of sudanese desert sheep. Small Ruminant Research, v.30, n.6, p.147-151, 1998.

GONZAGA NETO, S.; SILVA SOBRINHO, A.G.; ZEOLA, N.M.B.L. et al. Características quantitativas da carcaça de cordeiros deslanados Morada Nova, em função da relação volumoso:concentrado na dieta. Revista Brasileira de Zootecnia, v.35, n.4, p.1487-1495, 2006.

JOHNSON, D.D.; McGOWAN, C.H. Diet management effects on carcass atributes and meat quality of young goats. Small Ruminant Research, v.28, p.93-98, 1998.

LEITE, E.R. Manejo alimentar de caprinos e ovinos. In: WORKSHOP SOBRE CAPRINOS E OVINOS TROPICAIS, 1., 1999, Fortaleza. Anais... Fortaleza: Banco do Nordeste, 1999. p.52-56.

MATTOS, C.W.; CARVALHO, F.F.R; DUTRA JR., W.M. et al. Características de carcaça e dos componentes não-carcaça de cabritos Moxotó e Canindé submetidos a dois níveis de 
alimentação. Revista Brasileira de Zootecnia, v.36, n.6, p.2125-2134, 2006.

MEDEIROS, G.R. Efeito dos níveis de concentrado sobre o desempenho, características de carcaça e componentes não carcaça de ovinos morada nova em confinamento. Recife: Universidade Federal Rural de Pernambuco, 2006. 109p. Tese (Doutorado em Zootecnia) - Universidade Federal Rural de Pernambuco, 2006.

MOORE, J.A. POORE, M.H.; LUGINBUHL, J.M. By-product feeds for meat goats: effects on digestibility, ruminal environment, and carcass characteristics. Journal of Animal Science, v.80, p.1752-1758, 2002.

NOGUEIRA, D.M.; HOLANDA JR., E.; ARAÚJO, G.G. et al. Desempenho de carcaça de caprinos em sistema de produção orgânica na região semi-arida do Nordeste do Brasil. In: REUNIAO ANUAL DA SOCIEDADE BRASILEIRA DE ZootecniA, 41., 2004, Campo Grande. Anais... Campo Grande: Sociedade Brasileira de Zootecnia. (CD-ROM).

NATIONAL RESEARCH COUNCIL - NRC. Nutrient requirements of sheep. 6.ed. Washington, D.C.: National Academy Press, 1985. 99p.

SANTANA, G.Z.M.; NEIVA, J.N.M.; OLIVEIRA, A.L. et al. Rendimentos de carcaça e de cortes carneos de cordeiros santa Inês alimentados com dietas contendo subprodutos agroindustriais. In: REUNIAO ANUAL DA SOCIEDADE BRASILEIRA DE Zootecnia , 41., 2004, Campo Grande. Anais... Campo Grande: Sociedade Brasileira de Zootecnia. (CD-ROM).

SANTOS, N.M.; COSTA, R.G.; MEDEIROS, A.N. et al. Composição centesimal da buchada caprina pré-cozida produzida no Estado da Paraíba. In: REUNIAO ANUAL DA SOCIEDADE BRASILEIRA DE ZOOTECNIA, 42., 2005, Goiânia. Anais... Goiânia: Sociedade Brasileira de Zootecnia. (CD-ROM).

STATISTICAL ANALYSIS SYSTEMS - SAS. User's guide. Versão 8.0. Cary: SAS Institute, 1999. (CD-ROM).

SEN, A.R.; SANTRA, A.; KARIM, S.A. Carcass yield, composition and meat quality attributes of sheep and goat under semiarid conditions. Meat science, v.66, p.757-763, 2004.

SILVA SOBRINHO, A.G. Body composition and characteristics of carcass from lambs of different genotypes and ages at slaughter. Palmerston North: Massey University, 1999. 54p. Report (Post Doctorate in Sheep Meat Production) - Massey University, 1999.

SILVA SOBRINHO, A.G.; MACHADO, M.R.F.; GASTALDI, K.A.G. et al. Efeito da relação volumoso:concentrado e do peso ao abate sobre os componentes da perna de cordeiros Ile de France $\mathrm{x}$ Ideal confinados. Revista Brasileira de Zootecnia, v.31, n.2, p.1017-1023, 2002.

SILVA SOBRINHO, A.G.; GONZAGA NetO, S. [2004]. Produção de carne caprina e cortes da carcaça. Disponível em: $<$ http://www.capritec.com.br/pdf/produção carnecaprina. PDF>. Acesso em: 28/3/2004.

SIQUEIRA, E.R.; SIMÕES, C.D.; FERNENDES, S. Efeito do sexo e do peso ao abate sobre a produção de carne de cordeiros. Morfometria da carcaça, peso dos cortes, composição tecidual e componentes não constituintes da carcaça. Revista Brasileira de Zootecnia, v.30, n.4, p.1299-1307, 2001.

TAHIR, M.A; AL-JASSIM, A.F.; ABDULLA, A.H.H. Influence of live weight and castration on distribution of meat, fat and bone in the carcass of goats. Small Ruminant Research, v.14, p.219-223, 1994.

YAMAMOTO, S.M.; MACEDO, F.A.F.; ALCADE, C.R. et al. Características de carcaça de caprinos jovens, terminados com proteína by pass. In: REUNIÃO ANUAL DA SOCIEDADE BRASILEIRA DE ZOOTECNIA, 37., 2000, Viçosa, MG. Anais... Viçosa, MG: Sociedade Brasileira de Zootecnia, 2000. p.356.

YÁNEZ, E.A. Desenvolvimento relativo dos tecidos e características da carcaça de cabritos saanen, com diferentes pesos e níveis nutricionais. Jaboticabal: Universidade Estadual Paulista, 2002. 85p. Tese (Doutorado em Zootecnia) - Universidade Estadual Paulista, 2002.

ZUNDT, M.; MACEDO, F.A.F.; ALCADE, C.R. et al. Características de carcaça de caprinos alimentados com diferentes níveis energéticos. In: REUNIÃO ANUAL DA SOCIEDADE BRASILEIRA DE ZOOTECNIA, 38., 2001, Piracicaba. Anais... Piracicaba: Sociedade Brasileira de Zootecnia, 2001. p.992. 